\title{
Reconstructing the archosaur radiation using a Middle Triassic archosauriform tooth assemblage from Tanzania
}

\author{
Devin K Hoffman ${ }^{\text {Corresp., } 1}$, Hunter R Edwards ${ }^{1,2}$, Paul M Barrett ${ }^{3}$, Sterling J Nesbitt $^{1}$ \\ 1 Department of Geosciences, Virginia Polytechnic Institute and State University (Virginia Tech), Blacksburg, Virginia, United States of America \\ 2 Department of Geological Sciences, University of Cape Town, Rondebosch, South Africa \\ 3 Department of Earth Sciences, Natural History Museum, London, United Kingdom \\ Corresponding Author: Devin K Hoffman \\ Email address: devinkh5@vt.edu
}

Following the Permo-Triassic mass extinction, Archosauriformes - the clade that includes crocodylians, birds, and their extinct relatives outside crown Archosauria - rapidly diversified into many distinct lineages, became distributed globally, and, by the Late Triassic, filled a wide array of resource zones. Current scenarios of archosauriform evolution are ambiguous with respect to whether their taxonomic diversification in the Early-Middle Triassic coincided with the initial evolution of dietary specializations that were present by the Late Triassic or if their ecological disparity arose sometime after lineage diversification. Late Triassic archosauriform dietary specialization is recorded by morphological divergence from the plesiomorphic archosauriform tooth condition (laterally-compressed crowns with serrated carinae and a generally triangular lateral profile). Unfortunately, the roots of this diversification are poorly documented, with few known Early-Middle Triassic tooth assemblages, limiting characterizations of morphological diversity during this critical, early period in archosaur evolution. Recent fieldwork (2007-2017) in the Middle Triassic Manda Beds of the Ruhuhu Basin, Tanzania, recovered a tooth assemblage that provides a window into this poorly sampled interval. To investigate the taxonomic composition of that collection, we built a dataset of continuous quantitative and discrete morphological characters based on in situ teeth of known taxonomic status (e.g., Nundasuchus, Parringtonia: $\mathrm{N}=65$ ) and a sample of isolated teeth $(\mathrm{N}=31)$. Using crown heights from known taxa to predict tooth base ratio (= base length/width), we created a quantitative morphospace for the tooth assemblage. The majority of isolated, unassigned teeth fall within a region of morphospace shared by several taxa from the Manda Beds (e.g., Nundasuchus, Parringtonia); two isolated teeth fall exclusively within a 'Pallisteria' morphospace. A non-metric multidimensional scaling ordination ( $\mathrm{N}=67$ ) of 11 binary characters reduced overlap between species. The majority of the isolated teeth from the Manda assemblage fall within the Nundasuchus 
morphospace. This indicates these teeth are plesiomorphic for archosauriforms as Nundasuchus exhibits the predicted plesiomorphic condition of archosauriform teeth. Our model shows that the conservative tooth morphologies of archosauriforms can be differentiated and assigned to species and/or genus, rendering the model useful for identifying isolated teeth. The large overlap in tooth shape among the species present and their overall similarity indicates that dietary specialization lagged behind species diversification in archosauriforms from the Manda Beds, a pattern predicted by Simpson's 'adaptive zones' model. Although applied to a single geographic region, our methods offer a promising means to reconstruct ecological radiations and are readily transferable across a broad range of vertebrate taxa throughout Earth history. 


\section{Reconstructing the Archosaur Radiation using a Middle}

\section{Triassic Archosauriform Tooth Assemblage from Tanzania}

3 Devin K. Hoffman ${ }^{1}$, Hunter R. Edwards ${ }^{1,2}$, Paul M. Barrett ${ }^{3}$, Sterling J. Nesbitt ${ }^{1}$

$4{ }^{1}$ Department of Geosciences, Department of Geosciences, Virginia Polytechnic Institute and

5 State University (Virginia Tech), Blacksburg, VA, United States America

62 Department of Geological Sciences, University of Cape Town, Rondebosch 7701, South Africa

$7 \quad{ }^{3}$ Department of Earth Sciences, Natural History Museum, London, United Kingdom

8

9 Corresponding Author:

10 Devin K. Hoffman ${ }^{1}$

11926 West Campus Drive, Blacksburg, VA, 24061, USA

12 Email address: devinkh5@vt.edu 
13 Following the Permo-Triassic mass extinction, Archosauriformes - the clade that includes

14 crocodylians, birds, and their extinct relatives outside crown Archosauria - rapidly diversified

15 into many distinct lineages, became distributed globally, and, by the Late Triassic, filled a wide

16 array of resource zones. Current scenarios of archosauriform evolution are ambiguous with

17 respect to whether their taxonomic diversification in the Early-Middle Triassic coincided with

18 the initial evolution of dietary specializations that were present by the Late Triassic or if their

19 ecological disparity arose sometime after lineage diversification. Late Triassic archosauriform

20 dietary specialization is recorded by morphological divergence from the plesiomorphic

21 archosauriform tooth condition (laterally-compressed crowns with serrated carinae and a

22 generally triangular lateral profile). Unfortunately, the roots of this diversification are poorly

23 documented, with few known Early-Middle Triassic tooth assemblages, limiting

24 characterizations of morphological diversity during this critical, early period in archosaur

25 evolution. Recent fieldwork (2007-2017) in the Middle Triassic Manda Beds of the Ruhuhu

26 Basin, Tanzania, recovered a tooth assemblage that provides a window into this poorly sampled

27 interval. To investigate the taxonomic composition of that collection, we built a dataset of

28 continuous quantitative and discrete morphological characters based on in situ teeth of known

29 taxonomic status (e.g., Nundasuchus, Parringtonia: $\mathrm{N}=65)$ and a sample of isolated teeth $(\mathrm{N}=$

30 31). Using crown heights from known taxa to predict tooth base ratio (= base length/width), we

31 created a quantitative morphospace for the tooth assemblage. The majority of isolated,

32 unassigned teeth fall within a region of morphospace shared by several taxa from the Manda

33 Beds (e.g., Nundasuchus, Parringtonia); two isolated teeth fall exclusively within a 'Pallisteria'

34 morphospace. A non-metric multidimensional scaling ordination $(\mathrm{N}=67)$ of 11 binary

35 characters reduced overlap between species. The majority of the isolated teeth from the Manda 
36 assemblage fall within the Nundasuchus morphospace. This indicates these teeth are

37 plesiomorphic for archosauriforms as Nundasuchus exhibits the predicted plesiomorphic

38 condition of archosauriform teeth. Our model shows that the conservative tooth morphologies of

39 archosauriforms can be differentiated and assigned to species and/or genus, rendering the model

40 useful for identifying isolated teeth. The large overlap in tooth shape among the species present

41 and their overall similarity indicates that dietary specialization lagged behind species

42 diversification in archosauriforms from the Manda Beds, a pattern predicted by Simpson's

43 'adaptive zones' model. Although applied to a single geographic region, our methods offer a

44 promising means to reconstruct ecological radiations and are readily transferable across a broad

45 range of vertebrate taxa throughout Earth history. 
46

47

48

49

50

51

52

53

54

\section{Introduction}

Adaptive radiations, or evolutionary diversifications, play a critical role in the history of life as clades speciate and fill new ecological roles over geologically rapid time intervals (Simpson, 1944; Schluter, 1996). Although there are examples of adaptive radiations that are not speciose (e.g. Darwin's finches), or adaptively disparate (e.g. crotaphytine and oplurine iguanids), such a framework is still useful for structuring macroevolutionary questions and explaining present (and past) biological diversity (Gavrilets \& Losos, 2009). Adaptive radiations and the shifts in evolutionary rates associated with them are among the most studied aspects of evolutionary biology (e.g. Stanley, 1979; Losos \& Miles, 1994, 2002; Gavrilets \& Losos, 2009; Revell et al., 2018; Slater \& Friscia, 2019). However, empirical uncertainties remain regarding many of the properties of adaptive radiations (Gavrilets \& Losos, 2009; Slater \& Friscia, 2019), with the relative timings of lineage diversification and ecological disparity during adaptive radiations being one such problem. Does lineage diversification come first, followed by specialization and evolution within an 'adaptive zone' (Simpson, 1944, 1953) or does ecological specialization drive lineage diversification simultaneously (Schluter, 1996)? In the former case species fill the same resource zones using similar, ancestral morphological structures (e.g. identical tooth morphologies), whereas in the latter each species would be expected to have a unique, derived morphology for its resource zone at the start of the radiation (for an empirical example, see Slater \& Friscia, 2019). Determining which of these competing hypotheses operated in a particular case requires us to reconstruct an evolutionary radiation where a species-poor, adaptively restricted clade diversifies into a species-rich, adaptively disparate clade. 
69 archosauriforms recovered, rapidly diversified, and spread across Pangea to dominate terrestrial 70 ecosystems for the next 150 million years (Nesbitt, 2011; Ezcurra \& Butler, 2018). In addition to

71 Archosauriformes being a speciose and disparate radiation, they also provide an opportunity to

72 test adaptive radiations at a higher phylogenetic level. Lineage diversification of archosauriforms

73 was rapid after the PTME, and by the Middle Triassic many archosauriform clades had appeared

74 (Ezcurra, 2016; Foth et al., 2016; Ezcurra \& Butler, 2018). By the Late Triassic,

75 archosauriforms, including the crown group Archosauria, filled a wide variety of ecological

76 roles, from top predators to large herbivores, and were represented in terrestrial, freshwater, and

77 even marine ecosystems (e.g. Li et al., 2006; Butler et al., 2019). If lineage diversification occurs

78 first, followed by subsequent ecological disparity, we would expect Middle Triassic

79 archosauriforms from across the tree to represent a limited range of ecologies. The question then

80 arises, how can we best measure ecological disparity? Ecological disparity covers a variety of

81 physiological, behavioral, and morphological traits, but the nature of the fossil record limits its

82 measurement primarily to morphology. Previous work has used cranial morphology as a measure

83 of disparity (e.g. Foth et al., 2016); however, complete, or even partial, skulls are rare for Early-

84 Middle Triassic archosauriforms. Therefore, an alternative morphological system to approximate

85 ecological disparity is needed. In this study, we use teeth as an indicator of ecological disparity

86 because they have relatively high preservation potential (e.g. Turner-Walker, 2008) and offer a

87 direct link to ecology through diet (Lucas, 1979; Dessem, 1985; Scallon \& Shine, 1988; Sander,

88 1997; Linde, Palmer \& Gómez-Zurita, 2004; Santana, Strait \& Dumont, 2011; Zahradnicek et

89 al., 2014; Melstrom \& Irmis, 2019). Quantitative analyses of tooth morphology have previously

90 been used to document fossil assemblages with an emphasis on diet (Larson, 2008; Frey \&

91 Monniger, 2010; Larson \& Currie, 2013; Hendrickx, Mateus \& Araújo, 2015; Larson, Brown \& 
92 Evans, 2016; D’Amore et al., 2019; Melstrom \& Irmis, 2019). We consider diet as the aspect of

93 ecology of interest in this study because the relative ease of its inference from morphology alone 94 and the use of diet in previous studies of evolutionary radiations (e.g. Slater \& Friscia, 2019).

95 Although tooth assemblages are rare in Middle Triassic terrestrial strata, recent fieldwork $96(2007,2008,2012,2015,2017)$ in the Manda Beds of the Ruhuhu Basin, Tanzania (Sidor and 97 Nesbitt, 2017), has revealed a rich assemblage of archosauriforms known from postcrania and 98 partial crania, including teeth (e.g. Nesbitt et al., 2010; 2014; Smith et al., 2018). Specifically, 99 these teeth come from the middle and upper Lifua Member bone accumulations (Smith et al., 100 2018), except one tooth (NMT RB831) which comes from the lower bone accumulation (Nesbitt 101 et al., 2017; Smith et al., 2018), which are thought to be Anisian in age (Rubidge, 2005) but may 102 be as young as early Carnian (Ottone et al., 2014; Marsicano et al., 2016; Peecook et al., 2018; 103 Wynd et al., 2018). If the Anisian age is correct, then this is one of the oldest diverse 104 archosauriform faunas known that is also represented by specimens from historical collections 105 (e.g. Butler et al., 2009; 2017; Nesbitt et al., 2010; 2013; 2014; 2017; Barrett, Nesbitt \& 106 Peecook, 2015). Because this assemblage preserves members of ecological and phylogenetically 107 diverse archosauriform lineages (e.g., Dinosauriformes and Loricata) and is chronologically 108 between Early Triassic lineage diversification and Late Triassic ecological diversification it 109 represents an excellent candidate for testing the relative timing of ecological and lineage 110 diversification in the archosauriform radiation. Using a combination of information from these 111 new and historical collections, we quantify tooth disparity in this earliest part of the

112 archosauriform radiation to generate a morphospace visualization. From this we can assign 113 isolated teeth to specific taxon, visualize inter- and intraspecific variation as well as intra114 individual variation, and use this variation as a window into the ecological disparity of the 
115 archosauriforms within the Lifua Member assemblage. To achieve these goals, we use a

116 combination of in situ teeth from jaw elements assignable to particular species (Figure 1), and

117 isolated teeth attributable to Archosauriformes (Figure 2). Of particular interest is whether the

118 isolated teeth fall within or expand the region of morphospace, and therefore, feeding ecologies

119 occupied by the described Manda Beds taxa.

120 Institutional Abbreviations - NHMUK, Natural History Museum, London, U.K.; NMT,

121 National Museum of Tanzania, Dar es Salaam, Tanzania.

122

123

Materials \& Methods

124

The 31 isolated teeth included in this study were collected from surface accumulations

during fieldwork in 2007, 2008, 2012, 2015, and 2017 from the Manda Beds of the Ruhuhu

126

Basin by a multi-institutional team (Sidor \& Nesbitt, 2017). All of the isolated teeth included in

127 this study are currently housed at Virginia Tech Department of Geosciences and will be

permanently reposited and managed in the National Museum of Tanzania. In addition to these

isolated teeth (seven of which were referred to Nundasuchus: see Nesbitt et al., 2014), we also

included teeth from within the tooth-bearing elements of five taxonomically distinct

RB426), Asilisaurus (NMT RB837), 'Pallisteria' (NHMUK PV R36620), and one currently

134 the isolated teeth to Archosauriformes on the basis of their serration morphology (Nesbitt, 2011,

135 character 128 , states $1 \& 2$ ) as well as their general ziphodont construction, including lateral 
138 we can confidently identify to Archosauriformes, we may have excluded unusual archosauriform

139 teeth that do not resemble their 'typical' condition. Therefore, our reconstruction of disparity

140 should be considered a minimum estimate.

141 To quantify tooth shape, linear measurements (total crown height, base width, and fore-

142 aft base length) and denticle counts were made following the protocol in Smith, Vann \& Dodson

143 (2005), although due to the smaller size of the teeth in our study, we used $1 \mathrm{~mm}$ denticle

144 densities, rather than $5 \mathrm{~mm}$ densities (Supplemental Data S1). All statistical analyses were

145 performed in R (v 3.1.2) and the RStudio console (v 1.1.383). All graphs of quantitative data

146 were made using the R package "ggplot2" (Wickham, 2009). To capture tooth disparity (from

147 log-transformed linear measurements), we used sum of variances with $95 \%$ predictive intervals

148 following the methodology of Larson, Brown \& Evans (2016). We chose to use sum of variances

149 as our measure of disparity owing to its prevalence in the literature and its robustness when

150 working with small sample sizes. Sample size varied from 2-14 teeth; however, sample size does

151 not significantly affect the sum of variance analysis (Ciampaglio, Kemp \& McShea, 2001). The

15214 teeth of Asilisaurus largely contributed base and width measurements because only three teeth

153 were complete enough to measure crown height. We constructed a linear model in R that predicts

154 the variable of tooth base shape (ratio of mesiodistal length over labiolingual width) by the

155 variables of total crown height and species-level assignment [=base shape $=$ total crown height *

156 species assignment]. The effects of each species on predicting tooth base shape were elucidated

157 using the R package "lsmeans" (Lenth, 2016) using a pairwise comparison in the model by

158 taxon. We plotted the teeth of known taxonomic affinity using ggplot2 (Wickham, 2009) to

159 produce a base morphospace into which we plotted results from the isolated teeth for

160 comparison. 
162 the teeth in this study resemble the hypothetical ancestral archosauriform tooth (serrated,

163 recurved, and laterally compressed: Nesbitt, 2011). In order to more fully capture and describe

164 the subtle variation of these teeth, a method of capturing discrete variation is needed. Non-metric 165 multidimensional scaling (NMDS) is an ordination method that visualizes variation that can

166 incorporate discrete qualitative features. We created a set of 11 binary characters for scoring 167 isolated and in situ teeth for NMDS (Table 1, Figure 3, Supplementa1 Data S2). All characters

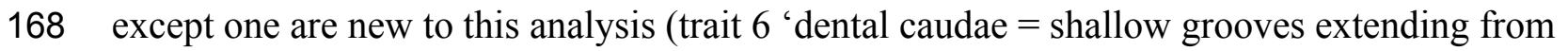
169 between two adjacent denticles present/absent' is taken from Abler [1992]). In order to avoid 170 circular reasoning when comparing our ecological signal to taxonomic and clade identity, we 171 selected traits that have not been used in phylogenetic analyses of archosauriforms previously in 172 the same form. The NMDS analysis was conducted in PAST (Hammer, Harper \& Ryan, 2001) 173 with a Bray-Curtis transformation. We ran an additional NMDS analysis in PAST using average 174 taxon and morphotype scores where traits were scored for each taxon with $>50 \%$ agreement of $i n$ 175 situ teeth. Traits for which $<50 \%$ of the specimens in the taxon or morphotype had the same 176 score were scored as unknown (“’?”).

178 Isolated Tooth Descriptions

179 Morphotype A: These teeth (Figure 2A-C) are generally triangular in outline in lateral view and 180 most are recurved (the point of the crown is distal to the distal-most extent of the crown base) 181 although the remainder have crown tips that are level with the distal-most extent of the crown 182 base. The labial and lingual sides of the crown lack ridges (i.e., no fluting), and the labial side of 183 the crown exhibits greater convexity than the lingual side. The mesial denticle series terminates 
184 more apically along the crown margin than the distal series, which continues along the entire 185 height of the crown though both start at the tip of the crown. The mesial denticle series is also 186 offset from the mesial-distal long axis of the crown base, deflecting to the lingual side toward the 187 crown base. The denticle densities range from 2-5 per mm. Denticle caudae (Abler, 1992), 188 which are shallow grooves extending from between two adjacent denticles, are often present and 189 directed parallel to the denticles. These denticle caudae are most easily observed in mesial or 190 distal view (Figure 3L).

191 In general, Morphotype A teeth strongly resemble both in situ and isolated teeth of 192 Nundasuchus (Figure 1; Nesbitt et al., 2014). Particularly important features are the presence of 193 denticle caudae, an unequal labial-lingual curvature, and the more apical termination of the 194 mesial denticle series relative to the distal denticle series. Also like Nundasuchus, Morphotype A 195 teeth exhibit a mix of states in the changing curvature of the mesial crown edge in lateral view, 196 with some teeth gradually changing angles and others exhibiting an abrupt shift in angle. The in 197 situ teeth of Nundasuchus can exhibit either state depending on the proximity of the mesial edge 198 of the crown to the distal edge of the preceding tooth. Although this combination of traits is only 199 found in Nundasuchus in the Manda Beds fauna, archosauriforms from the Middle and Late 200 Triassic elsewhere possess the same traits (e.g. de Oliveira \& Pinheiro, 2017; Schoch et al., 201 2018).

202 Morphotype B: These teeth (Figure 2D-F) are triangular in shape in lateral view and are 203 occasionally recurved, although in most the apical tip of the crown is approximately level with 204 the distal-most end of the crown base. Morphotype B tooth crowns lack fluting and, in contrast to 205 Morphotype A, the labial and lingual curvatures are equal. None of the teeth are bulbous (no 206 labiolingual measurements are greater than crown base width). In the majority of Morphotype B 
207 teeth the mesial margin of the crown possesses a single point where the angle of the mesial 208 carina changes abruptly. As in Morphotype A teeth, the mesial series of denticles in Morphotype 209 B teeth terminates on the crown further apically than the distal series, which often terminates at 210 the crown base. However, the mesial row of denticles is in line with the mesial-distal long axis of 211 the crown base. The denticle densities range from 3-8 per mm. Denticle caudae are present on 212 some of the teeth and are directed parallel to the denticles. Although these teeth bear a strong 213 resemblance to Morphotype A, they can be differentiated by their equal labial and lingual 214 curvatures. Morphotype B teeth are similar to some of the in situ and isolated Nundasuchus teeth 215 (Figures 1,2; Nesbitt et al., 2014).

216 Morphotype C: This morphotype (Figure 2G) is represented by a single tooth in our assemblage, 217 NMT RB831. The overall shape is tall, near conical, and recurved. The crown lacks fluting and 218 the labial curvature is greater than the lingual curvature. Although its labial-lingual curvature is 219 unequal, the mesial denticle series is positioned along the midline of the mesial-distal long axis. 220 The orientation of the mesial edge of the tooth changes gradually, forming a long, continuous 221 curve. The tooth is not bulbous. Denticle densities range from 2-4 per mm, and no denticle 222 caudae are present. There is no variation in either the shape or size of the denticles between the 223 mesial and distal series or along the length of the crown. Unlike either Morphotypes A or B, the 225 the distal series, just above the crown base. In general size and shape, as well as in many of its discrete features, the Morphotype C tooth is similar to the teeth of 'Pallisteria' based on our observations. The teeth of the latter taxon are large, conical, recurved, and possess unequal labial-lingual curvature. The denticle density is low $(<3$ per $\mathrm{mm})$ in the middle part of the tooth crown and denticles show little 
230 variation in shape or size. Unfortunately, none of the 'Pallisteria' teeth could be scored for Trait

2317 (termination height of the mesial denticle series; Table 1) due to poor preservation of the

232 denticles, which otherwise differentiates the Morphotype $\mathrm{C}$ tooth from morphotypes $\mathrm{A}$ and $\mathrm{B}$. If

233 Morphotype $\mathrm{C}$ is similar to, or is, 'Pallisteria', then subsequent 'Pallisteria' tooth discoveries

234 should be expected to have sub-equally extending mesial and distal denticle rows.

235

236 In situ Tooth Descriptions

237 Nundasuchus: We included a total of 13 Nundasuchus teeth (six in situ and seven isolated)

238 originally described in Nesbitt et al. (2014). The teeth range in height from 5.6-22 mm with

239 denticle densities from 2-5 per mm. All the teeth are labio-lingually compressed and are serrated

240 on both mesial and distal margins. Only two teeth (NMT RB48A, NMT RB48E) possess a

241 recurved tip that extends past the distal-most end on the tooth base (Figure 3). Most teeth are

242 smooth on the sides with a single exception exhibiting fluting (NMT RB48E: Figure 3). All of

243 the teeth possess unequal labial-lingual curvatures, a mesial row of denticles that terminates

244 higher on the tooth crown than the distal row of denticles, and a mesial carina that is offset from

245 the midline. Only two of the teeth possess dental caudae (NMT RB48A, NMT RB48G) and one

246 tooth is bulbous (NMT RB48C: Figure 3). In some teeth the mesial and distal denticle rows

247 differ in size and/or in shape. About half the teeth have a distinct point on the mesial margin

248 where the angle of the edge changes abruptly. For the in situ teeth, this seems to be related to

249 how close the tooth is to the preceding socket, with the closer the distance being associated with

250 an abrupt angle shift point.

251 Asilisaurus: We included 14 in situ teeth though only three of these included more than the very

252 base of the tooth. These three ranged in height from 1.6-2.9 $\mathrm{mm}$ and had a denticle density of $\sim 8$ 
253 per mm. The teeth are closely packed, ankylosed to the sockets, and peg-like in shape (Nesbitt et

254 al., 2010). All of the teeth have: smooth sides, equal labial-lingual curvature, and subeven mesial

255 and distal row of denticles. None of the Asilisaurus teeth possess dental caudae and the mesial

256 edge of the teeth changes angles gradually.

257 Parringtonia: Of the 14 teeth in the study, 12 were in situ and the other two larger, isolated teeth.

258 The teeth range in size from $2.5-21.6 \mathrm{~mm}$, though the tallest in situ tooth is $8.3 \mathrm{~mm}$, and the

259 denticle densities vary from 5-15 per mm. Most of the Parringtonia teeth lacked crown tips,

260 though the two complete teeth are not recurved (Figure 2I). All of the teeth are labio-lingually

261 compressed and possess fluting and a mesial carina along the midline. The mesial and distal

262 denticle series of all the teeth remain constant in both shape and size, though the mesial denticle

263 series terminates higher on the crown than the distal series. In all the teeth the mesial edge angle

264 changes gradually.

265 NMT RB187: All 13 teeth of the teeth included from NMT RB187 are in situ. The labio-

266 lingually compressed teeth range from 5.3-13.4 $\mathrm{mm}$ tall with denticle densities of 8-14 per $\mathrm{mm}$.

267 All of the teeth are recurved, fluted, and lack dental caudae (Figure 1E,F). The mesial edge of the

268 teeth changes gradually and follows the mesial-distal long axis. In teeth with preserved crown

269 tips the shape of the denticles remains constant. Of all the taxa included here, NMT RB187

270 exhibits the greatest degree of recurvature.

271 'Pallisteria': We included 11 in situ teeth from the left and right maxillae and the left premaxilla

272 of a single individual of 'Pallisteria' (NHMUK PV R36620). These teeth are the largest of all

273 the taxa, ranging from $36.1-70.3 \mathrm{~mm}$, and have the lowest density, from 2-3 per $\mathrm{mm}$. All except

274 the two premaxillary teeth are recurved and all have smooth crowns and lack dental caudae.

275 Most of the teeth have uneven labial-lingual curvature and a mesial edge that changes angles 
276 gradually. The mesial carina is offset from the mesiodistal long axis in most the teeth and the

277 denticles remains constant in shape and size along the height of the crown.

278

279 Results

280 For our linear model we predicted the tooth base shape (ratio of labiolingual base width

281 to mesiodistal base length) using the total apicobasal crown height and the taxonomic affinity of

282 the tooth (base $\sim$ tch + taxon) with the $\operatorname{lm}($ ) command in base R (Table 2). We found that tooth

283 height was not a significant predictor of base shape $(\mathrm{p}=0.0933$. We used the $\mathrm{R}$ package

284 "lsmeans" to further investigate the differences between the species' tooth shape (Table 3). From

285 this metric NMT RB187 has a significantly higher base shape ratio than all other taxa except

286 Parringtonia $(\mathrm{p}=0.3788)$.

287

The sum of variances analysis (Figure 4) included all known Manda Beds archosauriform

288

289

290

291

292

293

294

295

296

297

298

taxa with associated dentition and two of the three morphotypes, as only a single tooth of

Morphotype $\mathrm{C}$ is present in our assemblage. These variances provide a quantification of

intraspecific variation in tooth size and shape, and allow for an equal interspecific comparison.

Mean variances ranged from a low of $0.02 \log$ units in 'Pallisteria', two large isolated teeth of

Parringtonia, and Morphotype B, to a high of 0.145 log units in Morphotype A (Figure 4).

More useful for visualizing variation than the linear model and lsmeans contrasts are

morphospace plots of the teeth from our generically determinate specimens, with the isolated,

unidentified teeth added for comparison. There is much overlap in morphospace occupancy,

particularly on the left side (shorter height) portion of the graph, although 'Pallisteria' occupies

its own section of morphospace in taller crown heights (Figure 5). Teeth towards the bottom of

the morphospace (lower base ratio) are more rounded and cone-like, whereas those with higher

Peer] reviewing PDF | (2019:07:39444:1:1:NEW 7 Sep 2019) 
299 base ratios are more laterally compressed. With size alone two of the Morphotype A teeth fall in

300 'Pallisteria' morphospace and the Morphotype C tooth with Nundasuchus morphospace contrary

301 to the discrete descriptive predictions. The relationship between base width and mesiodistal base

302 length provides little more distinction of the taxa included, and the impact of crown size is still

303 evident (Figure 6). In general the ratio of base mesiodistal length and labiolingual width follows

304 a linear trend controlled by size. Since size seemed to be the primary driver of differences

305 between taxa, we modified the two previous comparisons in order to control for size. Again we

306 compared the tooth base ratio to total crown height, this time with crown height divided by fore-

307 aft base length to create a ratio for the lateral profile (Figure 7). This caused even greater overlap

308 in morphospace than the non-size controlled comparison (Figure 5) as 'Pallisteria' was no

309 longer separated from the other taxa (Figure 7). Similarly, when we compared base width

310 divided by height to fore-aft base length divided by height to control for size the morphospace of

311 taxa increased in overlap (Figure 8). Again, 'Pallisteria' was no longer in a distinct region of

312 morphospace (Figure 8). However, the general trend recovered in Figure 6 remained even once

313 we controlled for size, though the deviation had increased (Figure 8).

314 A total of 21 isolated teeth and 46 in situ teeth of known taxonomic identity were

315 complete enough to be scored for the NMDS analysis. Convex hulls are more differentiated than

316 in the quantitative morphospace, with almost no overlap of Nundasuchus with either NMT

317 RB187 or Parringtonia (Figure 9). Overlap of NMT RB187 and Parringtonia remains, but most

318 of the isolated teeth fall exclusively within or adjacent to the zone of Nundasuchus and

319 'Pallisteria' (Figure 9). The high degree of overlap between Parringtonia and NMT RB187

320 likely reflects their often-shared feature of having parallel ridges (fluting) along the labial and

321 lingual sides of the tooth crown. The only other tooth in the study with fluting is a single

Peer] reviewing PDF | (2019:07:39444:1:1:NEW 7 Sep 2019) 
322 example referred to Nundasuchus. The use of taxa and morphotype 'averages' in traits reveals

323 similar groupings to the complete dataset, with average morphotype scores between those of

324 known taxa (Figure 10).

325

326

327

328

329

330

331

332

333

334

335

336

337

338

339

340

341

342

343

344

\section{Discussion}

We present the first quantitative description of a Middle Triassic archosauriform tooth assemblage, which reveals substantial conservation of tooth morphology at the beginning of the archosaur radiation. Intraspecific variation appears to be as great, if not greater, than interspecific variation. Morphotype A displays the greatest variance in tooth size in the sample, although Nundasuchus has a very similar sum of variance structure (Figure 4). Driving at least part of the pattern we see in our disparity analysis is whether more than a single individual of a given taxon is included in our study. For example, NMT RB187, 'Pallisteria', and Parringtonia all display low disparity, but our sample includes only elements from a single individual of each taxon, whereas the Nundasuchus sample includes in situ teeth from one lower jaw (the holotype specimen) and associated isolated teeth assigned to the holotype (Figure 4). Although two of the isolated teeth from our assemblage fall exclusively within the 'Pallisteria' quantitative morphospace, most of the isolated teeth fall within a zone of overlap between Nundasuchus, NMT RB187, and Parringtonia (Figure 5). Much of this quantitative variation reflects body size (Figure 6). Nundasuchus and 'Pallisteria' are much larger than the other taxa, which helps to differentiate their morphospace from that of smaller-bodied taxa. Asilisaurus is the smallest taxon in our sample, but there is postcranial evidence of a larger silesaurid in the Lifua assemblage (possibly a very large individual of Asilisaurus; Barrett, Nesbitt \& Peecook, 2015) that would be comparable in size to Nundasuchus and 'Pallisteria'. Recovery of teeth from 
345 silesaurid individuals of this larger size might reduce some of the differentiation between them,

346 Nundasuchus, and 'Pallisteria' though we would still expect silesaurid teeth to be smaller

347 relative to the same body size. By controlling for size in our analysis on linear measurements,

348 much of the morphospace differentiation, particularly for the large-bodied 'Pallisteria' (Figures

$3497 ; 8$ ), was lost. Although size can be an important consideration when reconstructing diet, this

350 demonstrates that when attempting to reconstruct general tooth shape distinctions between taxa

351 size should be controlled. Additional, it is worth noting that our study lacks ontogenetic data.

352 Because we are unable to tell the age of the isolated teeth and the maximum body size, and the in

353 situ specimens do not capture an ontogenetic series, we may miss important disparity changes

354 from ontogeny. The inclusion of isolated teeth should capture some of the ontogenetic variation

355 not found in our in situ specimens, yet likely not the entire range.

356

The NMDS ordination improves the differentiation of taxa, with Asilisaurus and the

357 large-bodied predator 'Pallisteria' more clearly separated from the still overlapping undescribed

358 pseudosuchian, and Parringtonia and Nundasuchus exhibiting wide variation in morphospace

359 overall, bridging the space between all taxa, and overlapping a substantial part of 'Pallisteria'

360 morphospace (Figure 9). These results identify two general areas of morphospace, one shared by

361 the undescribed pseudosuchian and Parringtonia and the other by Nundasuchus and

362 'Pallisteria'. The teeth of Parringtonia and the undescribed pseudosuchian share several

363 features, notably presence of fluting, a mesial carina along the midline tooth axis, and a high

364 denticle density ( $\geq 3$ per $\mathrm{mm}$ ). By contrast, Nundasuchus and 'Pallisteria' teeth lack fluting,

365 possess an offset mesial carina, unequal labial/lingual curvature, and have a low denticle density

$366(<3$ per $\mathrm{mm})$. This result is further supported when the average or typical score of each taxon is

367 used, with NMT RB187, Asilisaurus, and Parringtonia clustering together versus Nundasuchus 
368 and 'Pallisteria' on the other side of morphospace (Figure 10). Given that many of the isolated

369 teeth resemble those of Nundasuchus, it is not surprising that most of the isolated teeth fall

370 within the convex hull defined by Nundasuchus (Figure 9). We cannot, however, definitely

371 assign these teeth to Nundasuchus due to the overlap in discrete characters among our included 372 taxa.

373 Our results using both methods demonstrate that many of the isolated teeth resemble 374 those from currently recognized taxa. However, several teeth fall outside of the morphospace 375 defined by known taxa and could indicate either intraspecific variation (due to heterodonty or 376 ontogeny) or could represent other, as yet unsampled, taxa. Our methodologies are flexible and 377 the datasets can incorporate additional specimens as they are excavated, so these approaches 378 could be applied to other tooth assemblages throughout the Triassic across a broad range of 379 spatial, temporal, and taxonomic scales.

380 Ecological Differentiation. There are some hints of dietary separation between large381 and small-bodied archosaurs based on minor changes in tooth morphology and consideration of

382 body size. However, our results, which show high degrees of overlap in tooth morphology

383 suggest that ecological differentiation, at least in diet, appears to lag behind lineage

384 diversification, at least with respect to Manda archosauriforms. Four of the five recognized taxa 385 included here possess ziphodont dentitions (=labiolingual narrow crown [labiolingual width $<$ $38660 \%$ of mesiodistal length], recurved, typically serrated carinae, and no constriction at the cervix 387 sensu Hendrickx, Mateus \& Araújo, 2015) indicative of a carnivorous diet. Only Asilisaurus 388 differs in possessing a conidont dentiton (=conical crowns with small denticles or no denticles, 389 and typically fluted sensu Hendrickx, Mateus \& Araújo, 2015). Conidonty is present in 390 spinosaurids, many crocodylians, marine reptiles, and pterosaurs (Hendrickx, Mateus \& Araújo, 
391 2015) and has been linked to piscivory. Following this criterion Asilisaurus would be categorized

392 as a potential piscivore. However, dietary reconstructions of Silesaurus opolensis, another

393 silesaurid possessing similar dentition to Asilisaurus, have been herbivorous or omnivorous

394 based upon dental microwear (Kubo \& Kubo, 2014) or insectivorous based upon coprolites

395 (Qvarnström et al., 2019). Thus, in the Manda Beds tooth assemblage, there are two large-bodied

396 carnivores (Nundasuchus and 'Pallisteria'), two small-bodied carnivores (Parringtonia and an

397 undescribed pseudosuchian), and one small-bodied, non-carnivore (Asilisaurus). The Middle

398 Triassic Manda Beds may, therefore, be capturing the beginning of the 'Explosive Phase' of

399 Simpson's (1944) theoretical model as lineages split and begin to move towards new adaptive

400 zones. Further tooth assemblages will need to be evaluated to see if this is a broader trend that

401 holds across the Triassic archosaur radiation. We posit that the qualitative NMDS ordination

402 method gives us the necessary lens for testing this hypothesis.

403

404 Conclusions

405 Simple quantitative measures of tooth shape were of limited use in characterizing the

406 Middle Triassic Manda Beds archosauriform tooth assemblage because of the highly conserved

407 morphology of many specimens. Instead, an ordination based on discrete characters provided a

408 more effective means of differentiating the teeth of distinct taxa. Nevertheless, we found little

409 evidence for significant ecological differentiation of tooth shape between the five taxa included

410 in our study. Most isolated teeth $(n=17 / 21)$ fall within the spectrum of recognized taxon

411 variation, and the remainder represent either unsampled taxa or unsampled intraspecific

412 variation. We interpret this as evidence that ecological disparity in diet lagged behind lineage

413 diversification during the archosauriform radiation following the PTME. This in turn indicates 
414 that at least in some adaptive radiations, the process of ecological breadth expansion in a clade

415 may be separate from the earlier lineage diversification as proposed by Simpson $(1944 ; 1953)$.

416 Our relatively simple metrics can be used to describe subtle differences in tooth

417 morphology. These objective methods for grouping teeth provide a complimentary method for

418 assigning teeth to dietary roles, a practice that typically relies on qualitative comparisons to the

419 teeth of extant taxa of known diet (e.g. Fraser \& Walkden, 1983; Sander, 1999; Barrett, 2000;

420 Hungerbühler, 2000) or other fossil taxa (e.g. Dzik, 2003; Hendrickx, Mateus \& Araújo, 2015;

421 de Oliveira \& Pinheiro, 2017). Furthermore, the methods applied herein provide an evaluation of

422 ecological disparity that is separate from the features used in phylogenetic analyses, so that we

423 can compare these two evolutionary phenomena independently. This method is readily

424 transferable to tooth assemblages from other localities pertaining to any vertebrate clade. Our

425 next step will be to apply this technique to richer Middle Triassic sites, as well as Late Triassic

426 sites, to understand how morphological and ecological diversity changed during the early stages

427 of the archosauriform radiation.

428

429 Acknowledgements

430 We thank Dr. Kate Langwig and Dr. Josef Uyeda for their assistance and advice with R Studio, 431 and the Virginia Tech Paleobiology Research Group for helpful comments. 


\section{Works Cited}

433 Abler WL. 1992. The serrated teeth of tyrannosaurid dinosaurs, and biting structures in other

434 animals. Paleobiology 18:161-183.

435

436

437

438

439

440

441

442

443

444

445

446

447

448

449

450

451

452

453

454

Barrett PM. 2000. Prosauropods and iguanas: speculation on the diets of extinct reptiles. In Sues HD, ed. Evolution of Herbivory in Terrestrial Vertebrates: Perspectives from the Fossil Record. Cambridge: Cambridge University Press 42-78.

Barrett PM, Nesbitt SJ, Peecook BR. 2015. A large-bodied silesaurid from the Lifua Member of the Manda beds (Middle Triassic) of Tanzania and its implications for body-size evolution in Dinosauromorpha. Gondwana Research 27:925-931.

Benton MJ, Newell AJ. 2014. Impacts of global warming on Permo-Triassic terrestrial ecosystems. Gondwana Research 25:1308-1337.

Butler RJ, Barrett PM, Abel RL, Gower DJ. 2009. A possible ctenosauriscid archosaur from the Middle Triassic Manda Beds of Tanzania. Journal of Vertebrate Paleontology 29:10221031.

Butler RJ, Nesbitt SJ, Charig AJ, Gower DJ, Barrett PM. 2017. Mandasuchus tanyauchen, gen. et sp. nov., a pseudosuchian archosaur from the Manda Beds (?Middle Triassic) of Tanzania. Journal of Vertebrate Paleontology 37:96-121.

Butler RJ, Jones AS, Buffetaut E, Mandl GW, Scheyer TM, Schultz O. 2019. Description and phylogenetic placement of a new marine species of phytosaur (Archosauriformes: Phytosauria) from the Late Triassic of Austria. Zoological Journal of the Linnean Society zlz014. 10.1093/zoolinnean/zlz014.

Chen Z-Q, Benton MJ. 2012. The timing and pattern of biotic recovery following the endPermian mass extinction. Nature Geoscience 5:375-383. 
455 Ciampaglio CN, Kemp M, McShea DW. 2001. Detecting changes in morphospace occupation 456 patterns in the fossil record: characterization and analysis of measures of disparity. $457 \quad$ Paleobiology 27:695-715.

458 D’Amore DC, Harmon M, Drumheller SK, Testin JJ. 2019. Quantitative heterodonty in 459 Crocodylia: assessing size and shape across modern and extinct taxa. PeerJ 7:e6485. $460 \quad 10.7717 /$ peerj.6485

461 de Oliveira TM, Pinheiro FL. 2017. Isolated archosauriform teeth from the Upper Triassic 462 Candelária Sequence (Hyperodapedon Assemblage Zone, Southern Brazil). Revista 463 Brasileira de Paleontologia 20:155-162.

464 Dessem D. 1985. Ontogenetic changes in the dentition and diet of Tupinambis (Lacertilia: 465 Teiidae). Copeia 1985:245-247.

466 Dzik J. 2003. A beaked herbivorous archosaur with dinosaur affinities from the early Late 467 Triassic of Poland. Journal of Vertebrate Paleontology 23:556-574.

468 Erwin DH. 1994. The Permo-Triassic extinction. Nature 367:231-236.

469 Ezcurra MD. 2016. The phylogenetic relationships of basal archosauromorphs, with an emphasis $470 \quad$ on the systematics of proterosuchian archosauriforms. PeerJ 4:e1778.

471 Ezcurra MD, Butler RJ. 2018. The rise of the ruling reptiles and ecosystem recovery from the 472 Permo-Triassic mass extinction. Proceedings of the Royal Society London B Biologial $473 \quad$ Science 285:1-7. 10.1098/rspb.2018.0361

474 Foth C, Ezcurra MD, Sookias RB, Brusatte SL, Butler RJ. 2016. Unappreciated diversification of 475 stem archosaurs during the Middle Triassic predated the dominance of dinosaurs. BMC $476 \quad$ Evolutionary Biology 16:1-188. 
477 Fraser NC, Walkden GM. 1983. The ecology of a Late Triassic reptile assemblage from

478

479

480

481

482

483

484

485

486

487

488

489

490

491

492

493

494

495

496

497

498

Gloucestershire, England. Palaeogeography, Palaeoclimatology, Palaeoecology 42:341365.

Frey E, Monninger S. 2010. Lost in action-the isolated crocodilian teeth from Enspel and their interpretive value. Palaeobiodiversity and Palaeoenvironments 90:65-81.

Gavrilets S, Losos JB. 2009. Adaptive Radiation: Contrasting Theory with Data. Science $323: 732-737$.

Godefroit P, Cuny G. 1997. Archosauriform teeth from the upper Triassic of Saint-Nicolas-dePort (northeastern France). Palaeovertebrata 26:1-34.

Hammer Ø, Harper D, Ryan P. 2001. PAST-Palaeontological statistics: Palaeontologia Electronica 25:2009.

Hendrickx C, Mateus O, Araújo R. 2015. A proposed terminology of theropod teeth (Dinosauria, Saurischia). Journal of Vertebrate Paleontology 35:e982797.

Hungerbühler A. 2000. Heterodonty in the European phytosaur Nicrosaurus kapffi and its implications for the taxonomic utility and functional morphology of phytosaur dentitions. Journal of Vertebrate Paleontology 20:31-48.

Kubo T, Kubo, MO. 2014. Dental microwear of a Late Triassic dinosauriform, Silesaurus opolensis. Acta Palaeontologica Polonica 59:305-313.

Larson DW. 2008. Diversity and variation of theropod dinosaur teeth from the uppermost Santonian Milk River Formation (Upper Cretaceous), Alberta: a quantitative method supporting identification of the oldest dinosaur tooth assemblage in Canada. Canadian Journal of Earth Sciences 45:1455-1468. 
499 Larson DW, Currie PJ. 2013. Multivariate analyses of small theropod dinosaur teeth and 500 implications for paleoecological turnover through time. PLoS One 8:e54329.

501 Larson DW, Brown CM, Evans DC. 2016. Dental disparity and ecological stability in bird-like 502 dinosaurs prior to the end-Cretaceous mass extinction. Current Biology 26:1325-1333.

503 Lenth RV. 2016. Least-Squares Means: The R Package lsmeans. Journal of Statistical Software 504 69:1-33. doi:10.18637/jss.v069.i01

505

Li C, Wu X-c, Cheng Y-n, Sato T, Wang L. 2006. An unusual archosaurian from the marine 506 Triassic of China. Naturwissenschaften 93:200-206.

507 Linde M, Palmer M, Gómez-Zurita J. 2004. Differential correlates of diet and phylogeny on the 508 shape of the premaxilla and anterior tooth in sparid fishes (Perciformes: Sparidae).

509 Journal of Evolutionary Biology 17:941-952.

510

Losos JB, Miles DB. 1994. Adaptation, constraint, and the comparative method: phylogenetic issues and methods. In: Wainwright PC, and Reilly SM, eds. Ecological morphology:

512 integrative organismal biology. Chicago: The University of Chicago Press, 60-98.

513 Losos JB, Miles DB. 2002. Testing the hypothesis that a clade has adaptively radiated: iguanid 514 lizard clades as a case study. The American Naturalist 160:147-157.

515 Lucas PW. 1979. The dental-dietary adaptations of mammals. Neues Jahrbuch für Geologie und $516 \quad$ Paläontologie, Monatshefte 8:486-512.

517 Marsicano CA, Irmis RB, Mancuso AC, Mundil R, Chemale F. 2016. The precise temporal 518 calibration of dinosaur origins. Proceedings of the National Academy of Sciences 519 113:509-513. 
520 Nesbitt SJ, Sidor CA, Irmis RB, Angielczyk KD, Smith RMH, Tsuji LA. 2010. Ecologically

521 distinct dinosaurian sister group shows early diversification of Ornithodira. Nature

522 464:95-98.

523 Nesbitt SJ. 2011. The Early Evolution of Archosaurs: Relationships and the Origin of Major 524 Clades. Bulletin of the American Museum of Natural History 352:1-292.

525 Nesbitt SJ, Butler RJ, Gower DJ. 2013. A new archosauriform (Reptilia: Diapsida) from the 526 Manda beds (Middle Triassic) of southwestern Tanzania. PLoS One 8:e72753.

527 Nesbitt SJ, Sidor CA, Angielczyk KD, Smith RMH, Tsuji LA. 2014. A new archosaur from the 528 Manda beds (Anisian: Middle Triassic) of southern Tanzania and its implications for 529 530 character optimizations at Archosauria and Pseudosuchia. Journal of Vertebrate Paleontology 34:1357-1382.

Nesbitt SJ, Butler RJ, Ezcurra MD, Barrett PM, Stocker MR, Angielczyk KD, Smith RM, Sidor 532 CA, Niedźwiedzki G, Sennikov AG, Charig AJ, 2017. The earliest bird-line archosaurs 533 and the assembly of the dinosaur body plan. Nature 544:484-487.

534 Ottone EG, Monti M, Marsicano CA, Marcelo S, Naipauer M, Armstrong R, Mancuso AC. 2014. 535 A new Late Triassic age for the Puesto Viejo Group (San Rafael depocenter, Argentina): 536 SHRIMP U-Pb zircon dating and biostratigraphic correlations across southern Gondwana. Journal of South American Earth Sciences 56:186-199. paleontology of the Triassic Ntawere Formation of northeastern Zambia, with special emphasis on the archosauromorphs. Journal of Vertebrate Paleontology 37:8-38. 
541 Qvarnström M, Wernström JV, Piechowski R, Tałanda M, Ahlberg PE, Niedźwiedzki G. 2019.

542 Beetle-bearing coprolites possibly reveal the diet of a Late Triassic dinosauriform. Royal $543 \quad$ Society Open Science 6:181042. 10.1098/rsos.181042

544 Raup DM. 1979. Size of the Permo-Triassic bottleneck and its evolutionary implications. $545 \quad$ Science 206:217-218.

546 Revell LJ, González-Valenzuela LE, Alfonso A, Castellanos-García LA, Guarnizo CE, Crawford 547 AJ. 2018. Comparing evolutionary rates between trees, clades and traits. Methods in Ecology and Evolution 9:994-1005.

549

550

551

552 553 554 555 556 557 558 559 560 561

562

Rubidge BS. 2005. 27th Du Toit Memorial Lecture: re-uniting lost continents-fossil reptiles from the ancient Karoo and their wanderlust. South African Journal of Geology 108:135172.

Sander PM. 1997. Teeth and jaws. In Currie PJ, and Padian K eds. Encyclopedia of Dinosaurs. San Diego: Academic Press. 717-725.

Sander PM. 1999. The microstructure of reptilian tooth enamel: terminology, function, and phylogeny. Münchner Geowissenschaftliche Abhandlungen Reihe A 38:1-102.

Santana SE, Strait S, Dumont ER. 2011. The better to eat you with: functional correlates of tooth structure in bats. Functional Ecology 25:839-847.

Schluter D. 1996. Ecological Causes of Adaptive Radiation: The American Naturalist 148:S40S64.

Schoch RR, Ullmann F, Rozynek B, Ziegler R, Seegis D, Sues HD. 2018. Tetrapod diversity and palaeoecology in the German Middle Triassic (Lower Keuper) documented by tooth morphotypes. Palaeobiodiversity and Palaeoenvironments 98:615-638. 
563 Sidor CA, Nesbitt SJ. 2017. Introduction to vertebrate and climatic evolution in the Triassic Rift

564 Basins of Tanzania and Zambia. Journal of Vertebrate Paleontology 37:1-7.

565 $10.1080 / 02724634.2017 .1420661$

566

567

568

569

570

571

572

573

574

575

576

577

578

579

580

581

582

583

584

Simpson GG. 1944. Tempo and Mode in Evolution, New York, Columbia University Press. - 1953. Major features of evolution, New York, Columbia University Press.

Slater GJ, Friscia AR. 2019. Hierarchy in adaptive radiation: A case study using the Carnivora (Mammalia). Evolution 73:524-539.

Smith JB, Vann DR, Dodson P. 2005. Dental morphology and variation in theropod dinosaurs: implications for the taxonomic identification of isolated teeth. The Anatomical Record 285:699-736.

Smith RM, Sidor CA, Angielczyk KD, Nesbitt SJ, Tabor NJ. 2018. Taphonomy and paleoenvironments of Middle Triassic bone accumulations in the Lifua Member of the Manda Beds, Songea Group (Ruhuhu Basin), Tanzania. Journal of Vertebrate Paleontology 37:65-79.

Stanley SM. 1979. Macroevolution, pattern and process. Baltimore, Maryland: Johns Hopkins University Press.

Turner-Walker G. 2008. The chemical and microbial degradation of bones and teeth. In: Pinhasi R, and Mays S eds. Advances in human palaeopathology. West Sussex John Wiley and Sons, Ltd. 3-29.Wickham H. 2009. ggplot2: elegant graphics for data analysis, New York, Springer.

Wynd BM, Sidor CA, Whitney MR, Peecook BR. 2018. The first occurrence of Cynognathus in Tanzania and Zambia, with biostratigraphic implications for the age of Triassic strata in 
southern Pangea. Vertebrate and climatic evolution in the Triassic rift basins of Tanzania and Zambia. Society of Vertebrate Paleontology Memoir 17:228-239.

587 Zahradnicek O, Buchtova M, Dosedelova H, Tucker AS. 2014. The development of complex

588 tooth shape in reptiles. Frontiers in Physiology 5:74. doi:10.3389/fphys.2014.00074.

589 Zverkov NG, Fischer V, Madzia D, Benson RB. 2018. Increased pliosaurid dental disparity

$590 \quad$ across the Jurassic-Cretaceous transition. Palaeontology 61:1-22. 


\section{Figure 1}

A sample of the in situ dental material used for baseline measurements in this study.

Parringtonia (NMT RB426) left dentary in A - lateral and B - medial (bottom) views and C right dentary in lateral and $\mathrm{D}$ - medial views. Undescribed archosauriform taxon (NMT RB187) right maxilla in E - lateral and F - medial view. Nundasuchus (NMT RB48) holotype right dentary in $\mathrm{G}$ - lateral and $\mathrm{H}$ - medial views. Asilisaurus (NMT RB 837) right dentary in I lateral and $\mathrm{J}$ - medial views, $\mathrm{K}$ - left maxilla in lateral and $\mathrm{L}$ - occlusal views, and $\mathrm{M}$ - right maxilla in lateral and $\mathrm{N}$ - occlusal views. Abbreviations: ap, ascending process of the maxilla; ds, dentary symphysis; ga, gastralia; mg, Meckelian groove; mt III, metatarsal III; nf, nutrient foramen; pp, palatal process. All scale bars $1 \mathrm{~cm}$. 


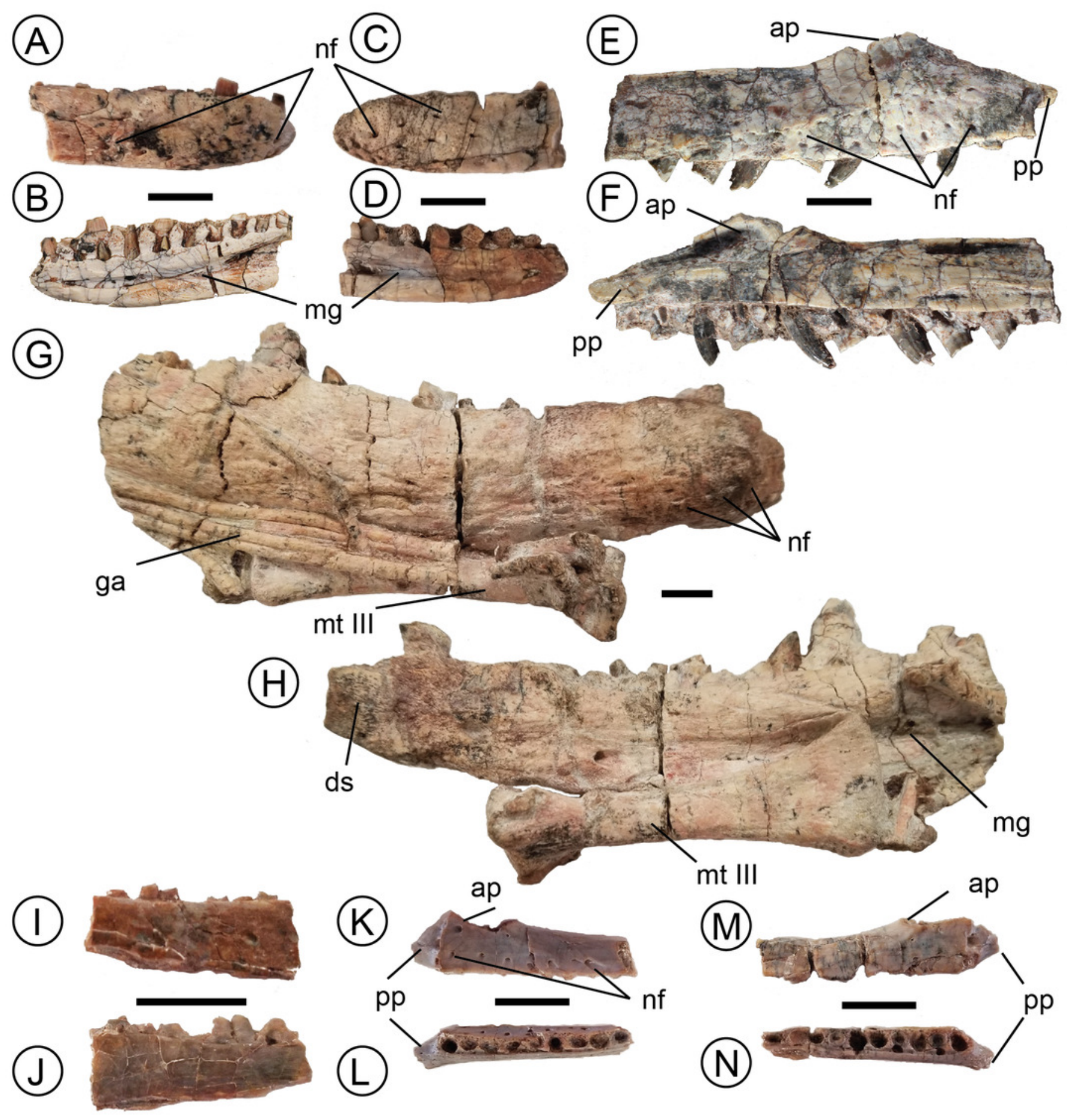




\section{Figure 2}

Examples of isolated teeth from the Manda Beds tooth assemblage.

Morphotype A specimens from left to right A - NMT RB807, B - NMT RB827, C - NMT RB809 in lateral and mesial views. Morphotype B, specimens from left to right, D - NMT RB810, E NMT RB819, F - NMT RB811 in lateral and mesial views. G - sole representative of Morphotype C NMT RB831 in lateral and mesial views. H-I - isolated teeth of known taxa. H Nundasuchus NMT RB48. I - Parringtonia NMT RB426 in lateral and mesial views. Scale bars A-C - $1 \mathrm{~cm} ; \mathrm{D}-\mathrm{F}-5 \mathrm{~mm} ; \mathrm{G}-1 \mathrm{~cm} ; \mathrm{H}-1 \mathrm{~cm} ; \mathrm{I}-2 \mathrm{~mm}$. 
(A)

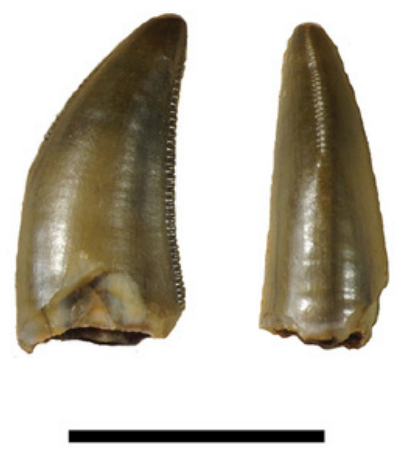

(D)
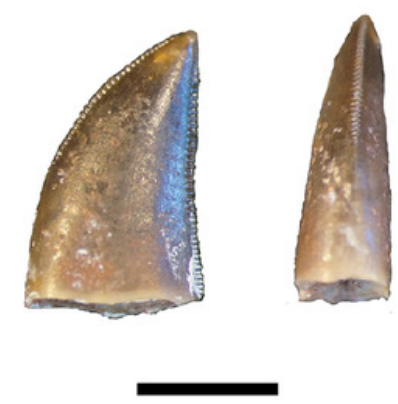

(E)

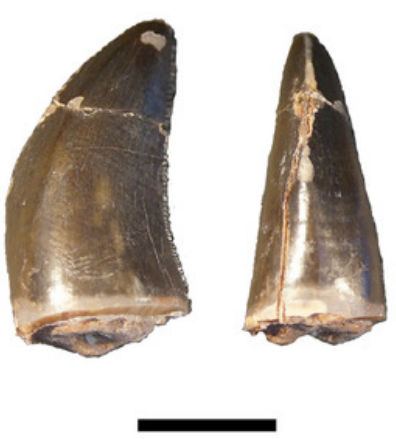

(B)

(C)

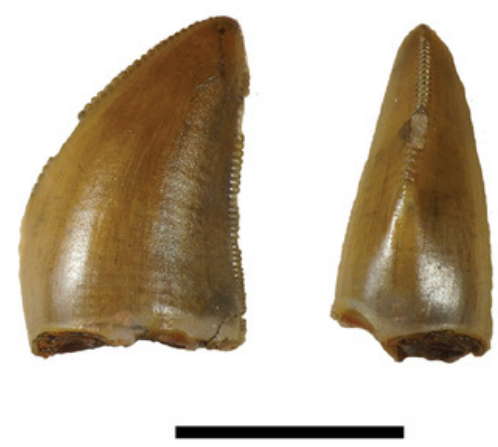

(F)
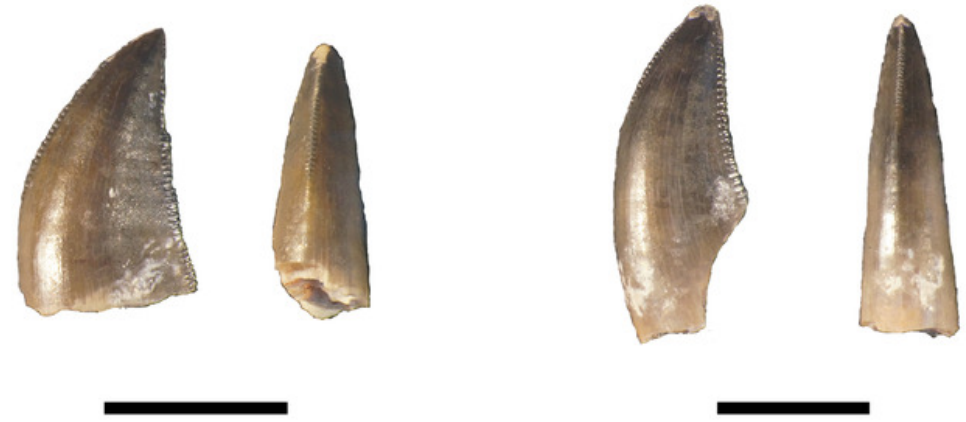

(H)
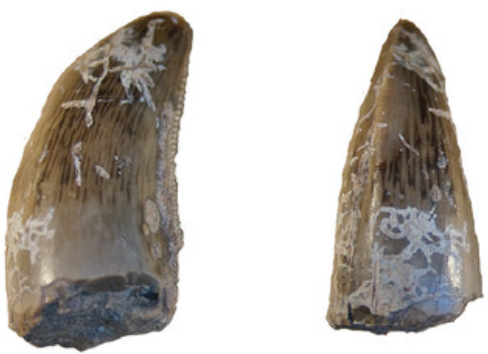

(1)

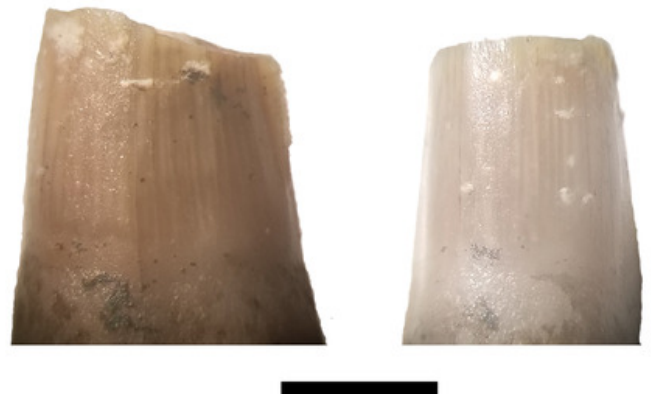




\section{Figure 3}

Visualization of discrete traits.

In all traits score 0 on left and score 1 on right. Trait 1, degree of recurvature, A - NMT RB819 and B - NMT RB827. Trait 2, fluting, C - NMT RB809 and D - NMT RB426. Trait 3, labiolingual curvature, E - NMT RB811 and F - NMT RB819. Trait 4, mesial margin angle, G - NMT RB811 and H - NMT RB827. Trait 5, labiolingual bulge, I - NMT RB811 and J - NMT RB48. Trait 6, dental caudae, K - NMT RB809 and L - NMT RB810. Trait 7, mesial vs distal serration series length, M - NMT RB831 and N - NMT RB810. Trait 8, denticle density per mm, O - NMT RB809 and P - NMT RB810, black lines equal $1 \mathrm{~mm}$. Trait 9, mesial margin alignment, Q - NMT RB810 and R - NMT RB809. Trait 10, mesial vs distal denticle density, S - NMT RB810 and T NMT RB809. Trait 11, denticle shape variation along crown, U - NMT RB810 and V - NMT RB48. 

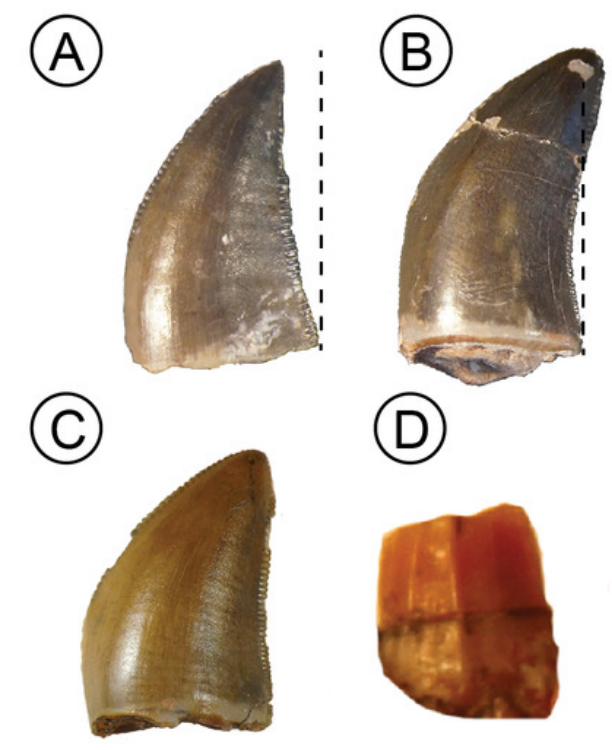

()
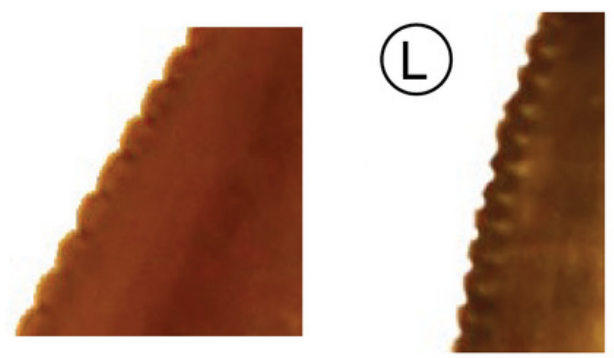

(i)
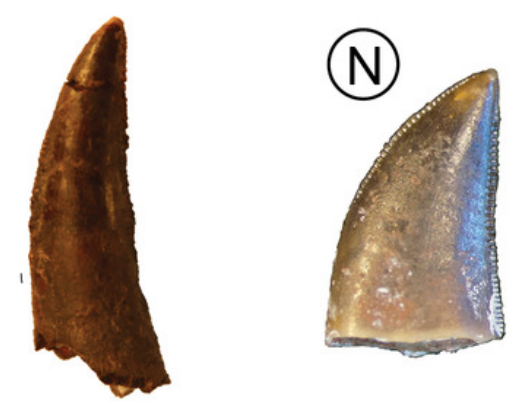

(E)

(F)

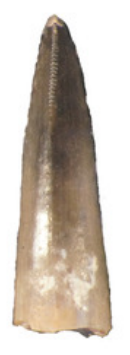

(D)

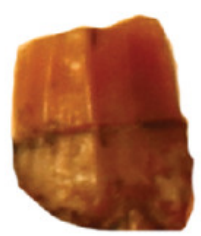

(0)
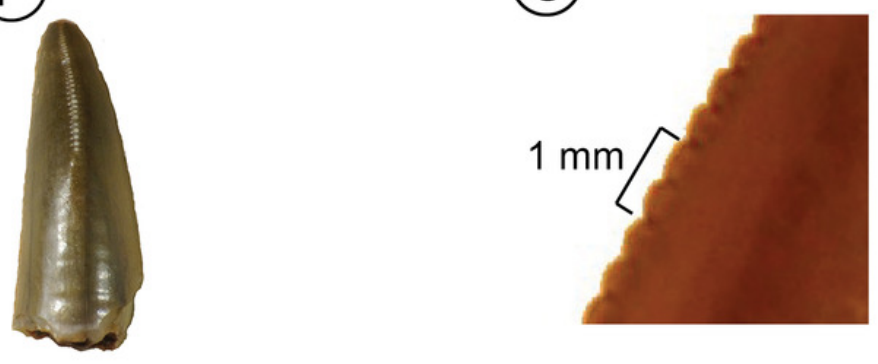

(P)

(G)
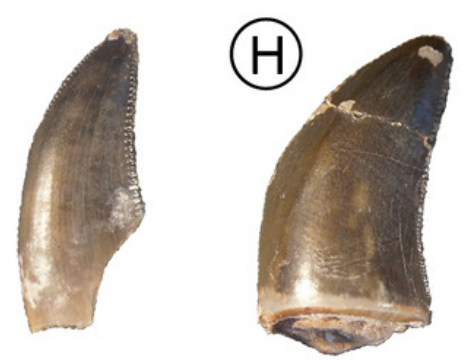

Q)

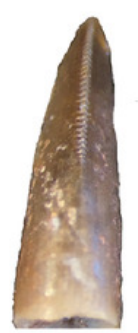

(R)

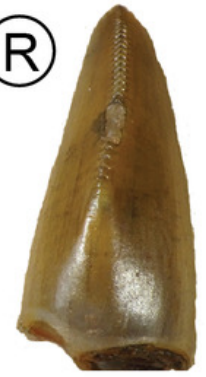

(1)

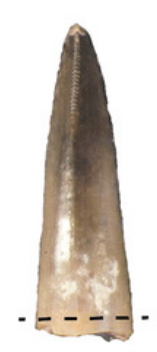

(I)

(s)

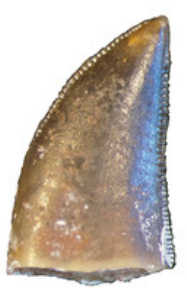

(T)

(v)

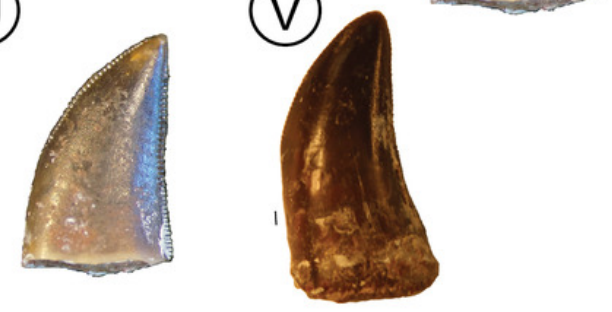

(1) 
Figure 4

Disparity of teeth measured by sum of variance

Disparity divided by taxon or morphotype. The sample sizes reflect the number of teeth with at least one of three measurements that was used to generate the predictive intervals.

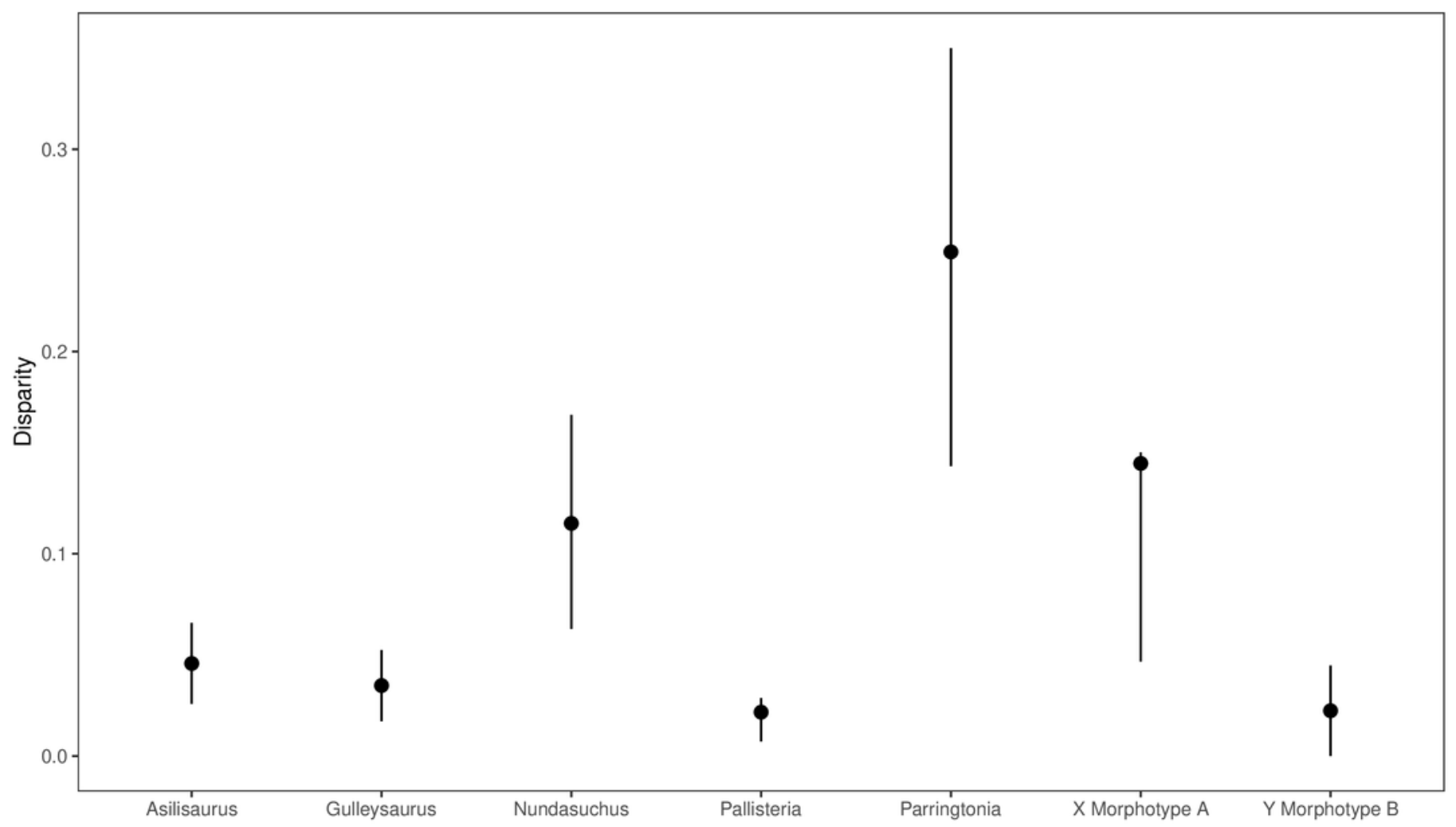


Figure 5

Relationship between height and base shape of teeth divided by taxon.

The taxonomically unidentified teeth fall within a variety of the morphospaces generated by known taxa, rendering unambiguous referrals impossible. Some genera exhibit much greater variation in base shape ratio than others, potentially indicating a greater level of within-taxon variation.

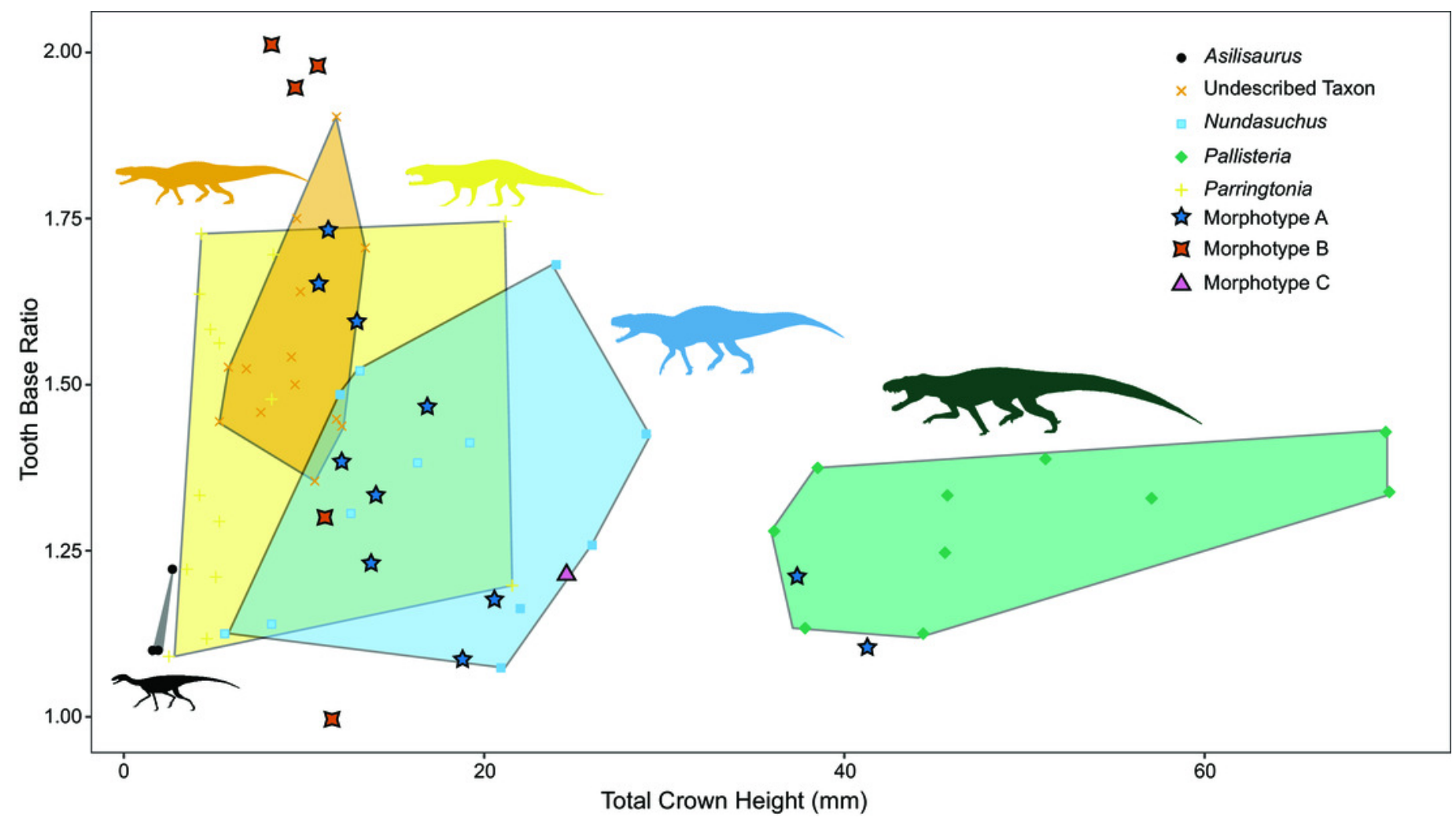


Figure 6

Relationship between base width and fore-aft base length divided by taxon.

The overall ratio of base shape appears to be highly conserved with little deviation from the general trend. Differentiation between genera appears to be driven primarily by size.

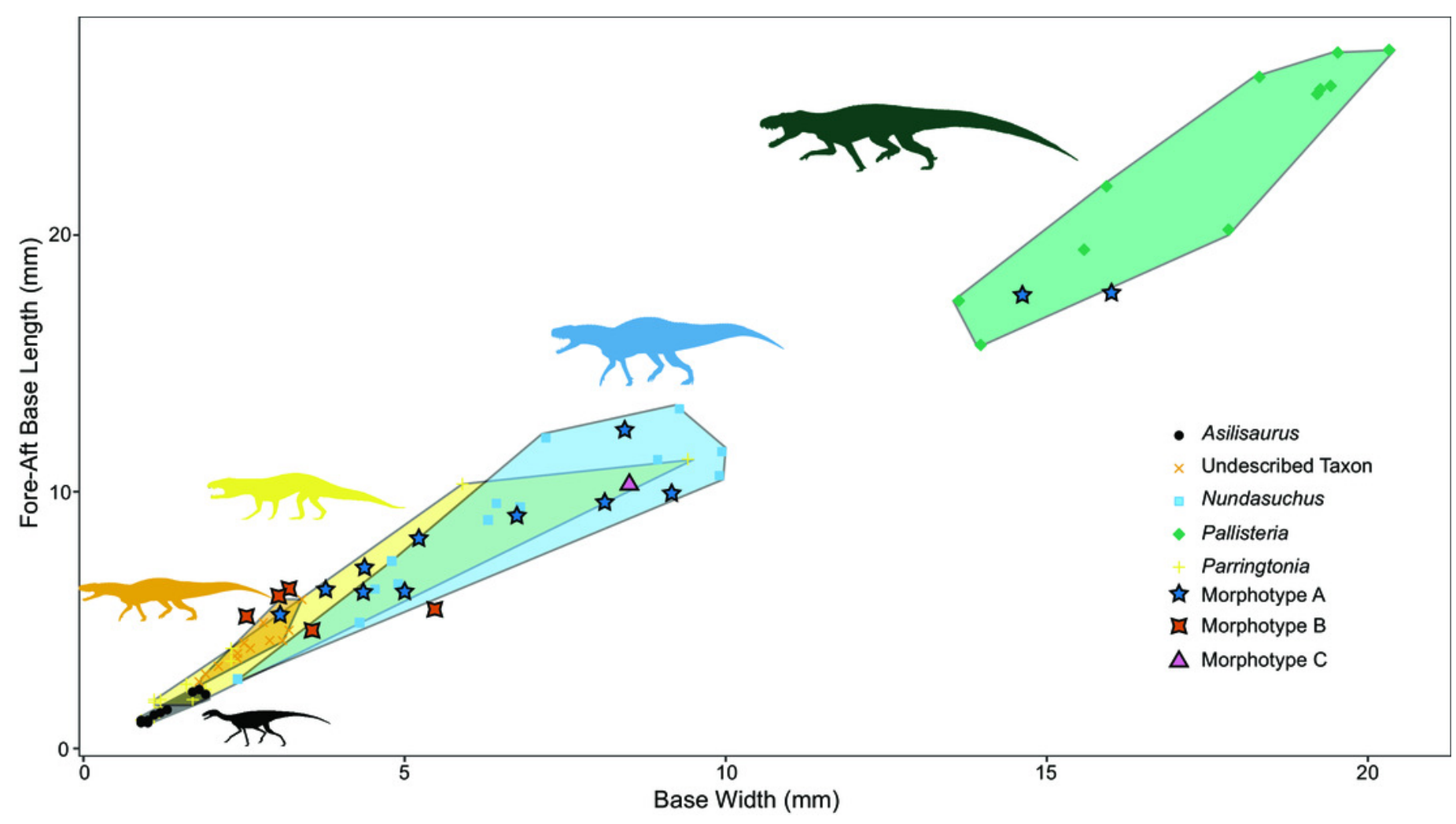


Figure 7

Relationship between height and base shape of teeth controlled for size.

Morpohotype B teeth appear to have the most labio-lingually compressed teeth. All taxa in our study exhibit a range of tooth base shapes, though some, such as Parringtonia, are more variable than others. The morphospaces of all taxa share large amounts of overlap.

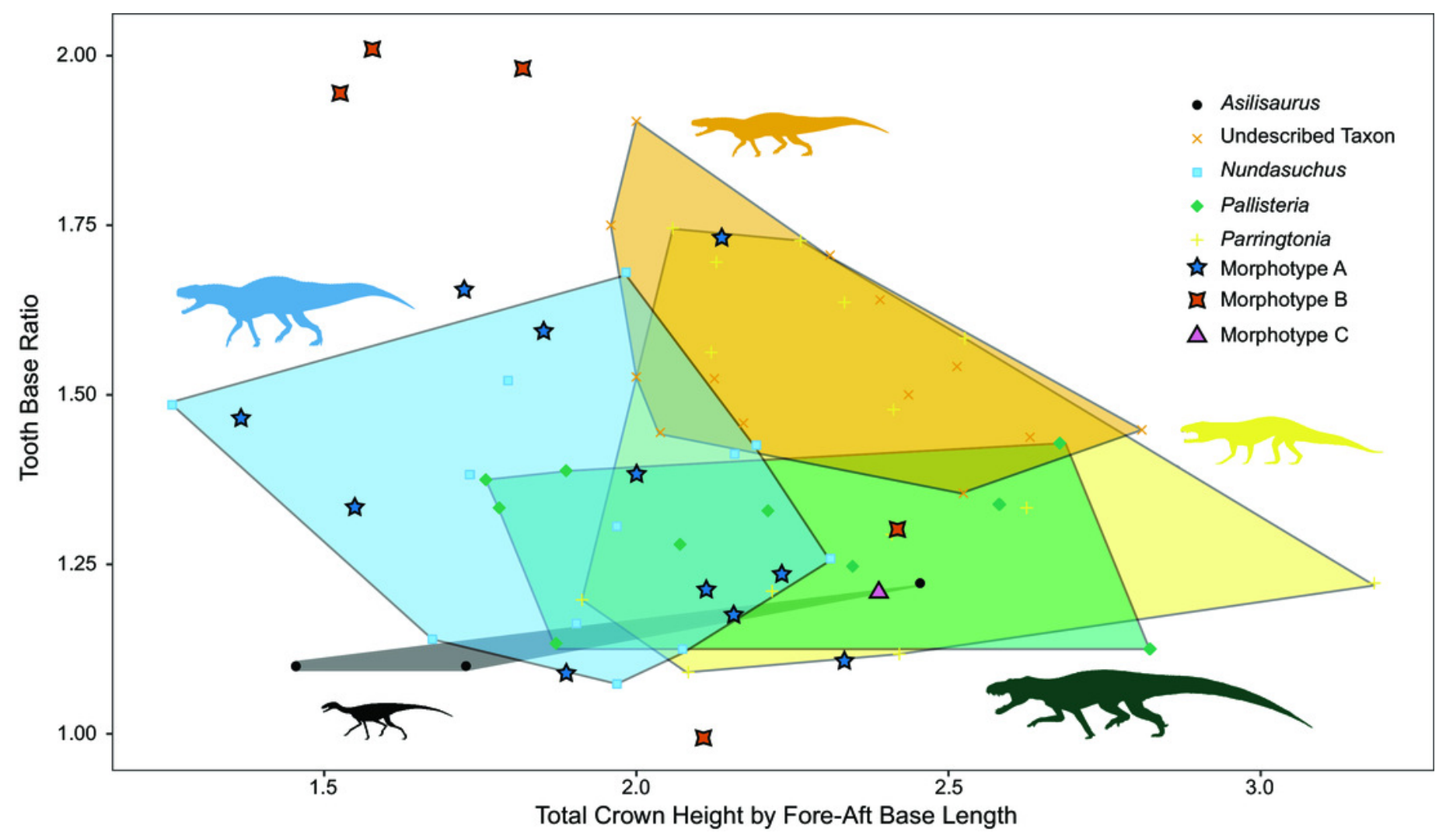


Figure 8

Relationship between base width and fore-aft base length divided by taxon controlled for size.

There is more deviation from the general trend in base ratio recovered in Figure 6, but does appear to remain. All taxa have some degree of morphospace overlap with the other taxa.

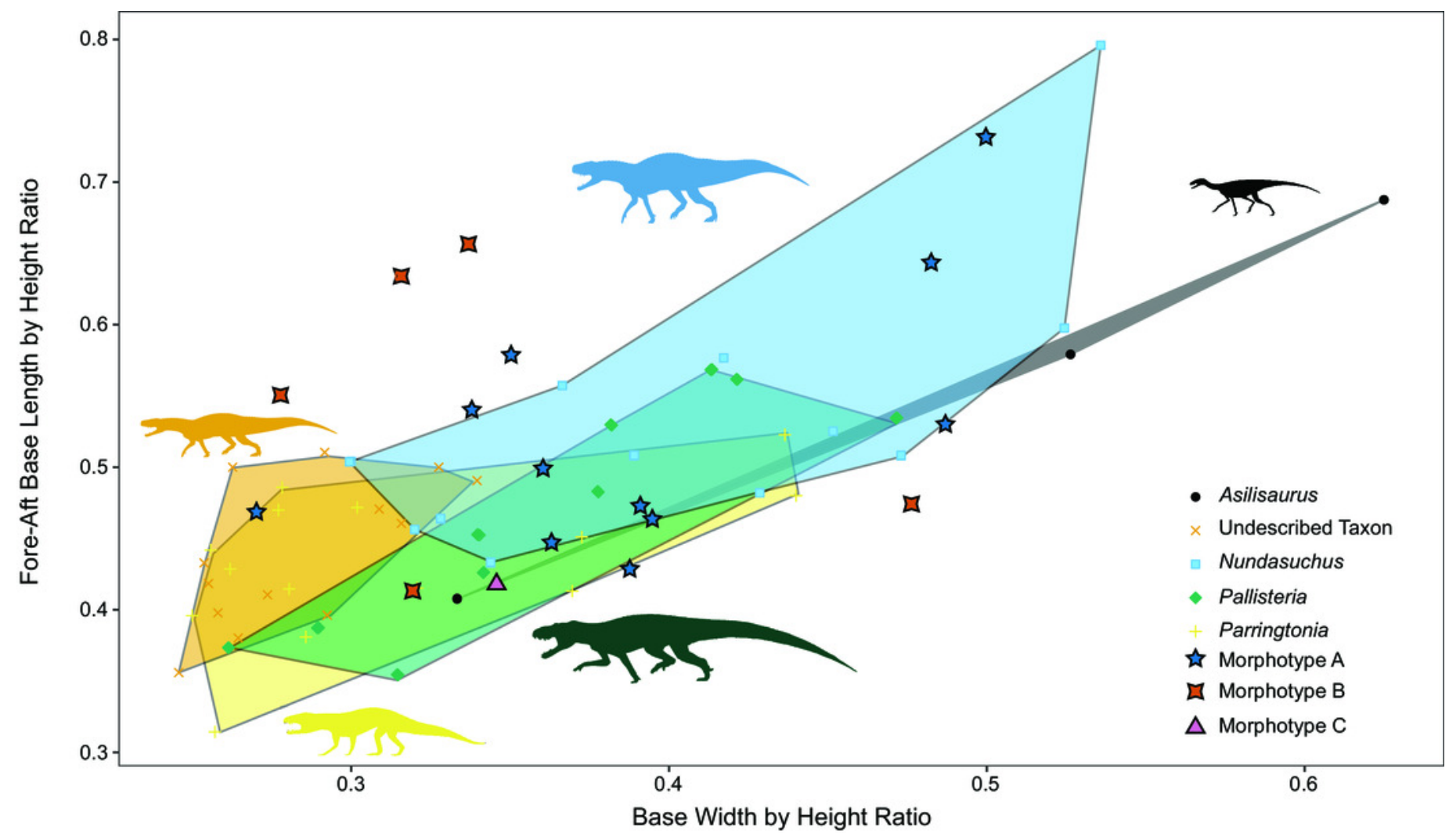




\section{Figure 9}

Ordination plot of first two major NMDS axes of tooth morphospace.

Colored, transparent polygons represent the convex hulls of known taxa. Each point represents a separate tooth scoring. Parringtonia and NMT RB187 (undescribed taxon) share almost the same morphospace and there is substantial overlap between Nundasuchus and 'Pallisteria' also. Morphotype A appears to be more variable than Morphotype B, which is clustered closer together within a subsection of overall Morphotype A morphospace. The proximity of Asilisaurus to Nundasuchus and 'Pallisteria' is likely an artifact of incomplete scorings for Asilisaurus teeth.

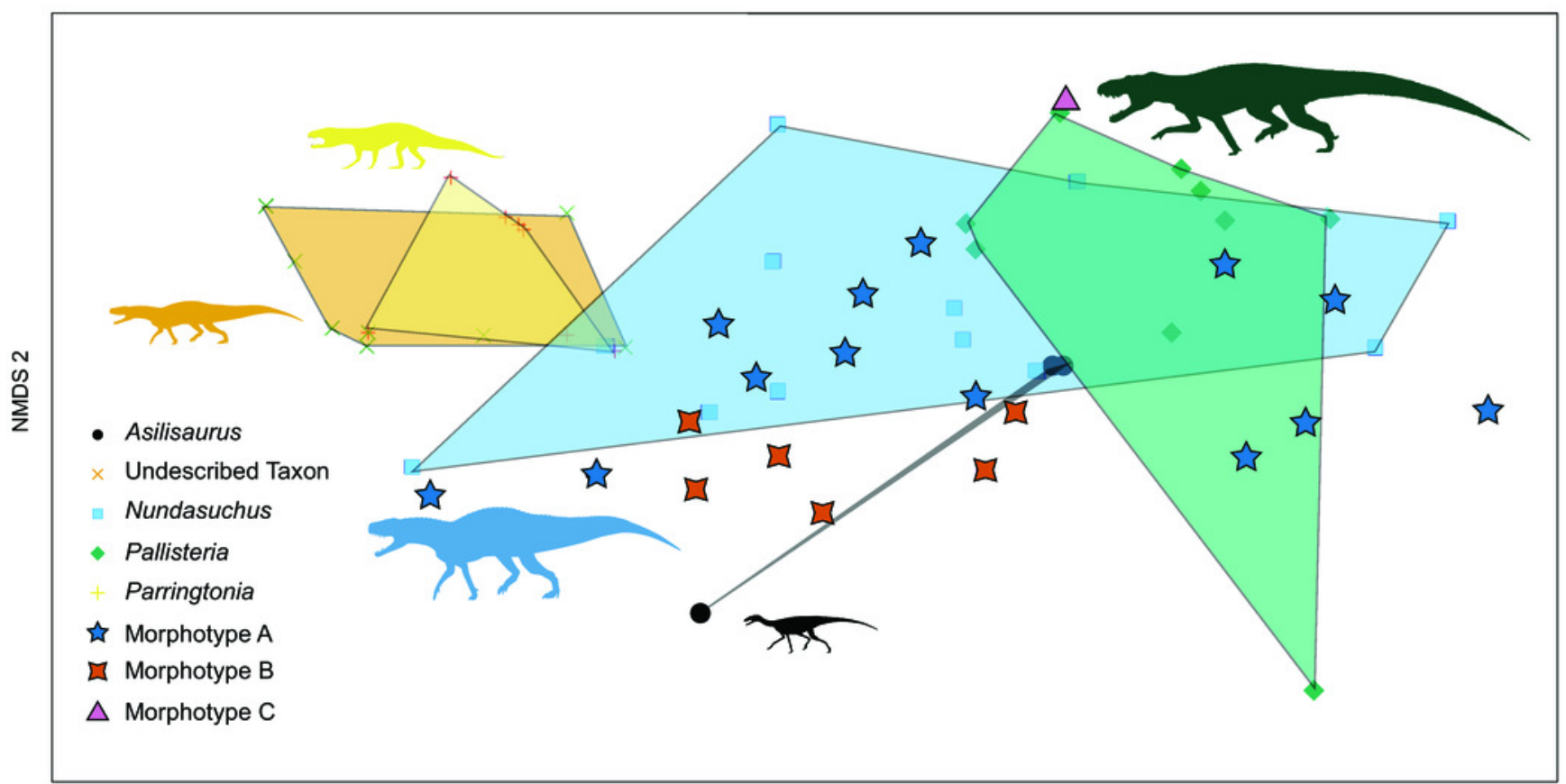

NMDS 1 
Figure 10

Ordination plot of first two primary NMDS axes of tooth "averages" morphospace.

Taxa scoring represent "average" scores for each taxon. Only Morphotype $\mathrm{C}$ is represented by a single tooth. When using typical scores for taxa we find Asilisaurus is no longer near Nundasuchus and 'Pallisteria' morphospace, but on the far side of ordination space.

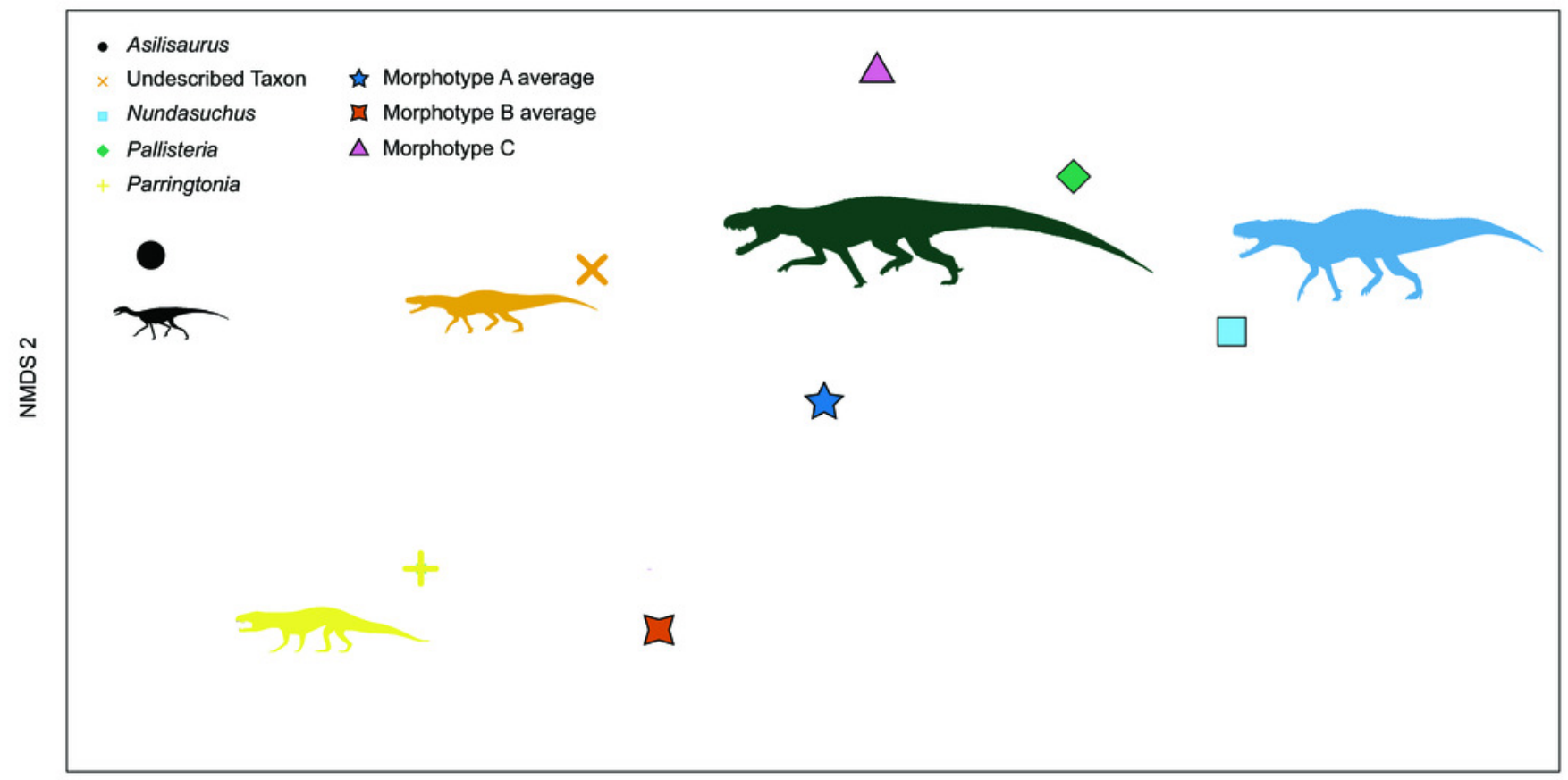

NMDS 1 


\section{Table 1 (on next page)}

Discrete character descriptions

Summary of the discrete, binary traits used for scoring teeth in the NMDS analysis. 


\begin{tabular}{|c|c|}
\hline & Description \\
\hline 1 & $\begin{array}{l}\text { Tooth apex, location, relative to the distal margin of the tooth base: tip mesial to or in the } \\
\text { same vertical plane as the distal edge }(0) \text { or tip is located more distal than the distal edge } \\
\text { (=recurved) (1) }\end{array}$ \\
\hline 2 & $\begin{array}{l}\text { Tooth lingual/labial, surfaces: texture is smooth (lack of crenulations, ridges, etc.) (0) or } \\
\text { surface texture possess a series of parallel ridges from tooth apex to base (=fluted) (1) }\end{array}$ \\
\hline 3 & $\begin{array}{l}\text { Tooth labial/lingual, shape: crown curvature unequal (one side expanded relative to other) } \\
\text { (0) or equal labial and lingual curvature (1) }\end{array}$ \\
\hline 4 & $\begin{array}{l}\text { Mesial tooth margin, shape: curvature angles change gradually }(0) \text { or angle changes abruptly } \\
\text { at a single discrete point along mesial edge (1) }\end{array}$ \\
\hline 5 & $\begin{array}{l}\text { Tooth crown, size: labiolingual widths dorsal to the tooth crown base are all less than the } \\
\text { crown base width (0) or a crown labiolingual width dorsal to the tooth crown base is greater } \\
\text { than the crown base width (1) }\end{array}$ \\
\hline 6 & $\begin{array}{l}\text { Mesial/distal crown margins, surfaces: denticle caudae (= grooves on crown surface from } \\
\text { between individual denticles) are absent (0) or present (1) (from Abler, 1992) }\end{array}$ \\
\hline 7 & $\begin{array}{l}\text { Mesial margin, length: mesial denticle row ends at a point sub-equal with distal denticle row } \\
(0) \text { or mesial denticle row ends significantly further apically on crown than distal row (1). } \\
\text { Can only be scored for teeth with both mesial and distal denticle series. }\end{array}$ \\
\hline 8 & $\begin{array}{l}\text { Mesial/distal margins, denticle density: number of mesial and distal denticles is }<3 \text { per } \mathrm{mm} \\
(0) \text {, or greater than or equal to } 3 \text { per mm (1). Measurements are taken near the middle of the } \\
\text { carina. }\end{array}$ \\
\hline 9 & $\begin{array}{l}\text { Mesial margin, location: vertical axis of the mesial carina is in line the mesial-distal long } \\
\text { axis }(0) \text { or laterally offset from the mesial distal long axis (1) }\end{array}$ \\
\hline 10 & $\begin{array}{l}\text { Mesial/distal margins, size: average size of mesial and distal denticles are the same (0) or } \\
\text { the average size of the mesial and distal denticles is different (1) }\end{array}$ \\
\hline 11 & $\begin{array}{l}\text { Mesial/distal margins, shape: lateral profile shape of mesial and distal denticles remains } \\
\text { constant (0) or denticles' lateral profile changes shape (e.g. rounded to square) (1) }\end{array}$ \\
\hline
\end{tabular}




\section{Table 2 (on next page)}

Results of linear model (base $\sim$ total crown height + taxon)

All measures of significance are calculated in reference to the intercept, Asilisaurus.

Therefore, while the undescribed pseudosuchian and Parringtonia can be differentiated in the model from Asilisaurus, the interrelationships are unknown. 


\begin{tabular}{lllll} 
& Estimate & Standard Error & t-value & p-value \\
\hline Asilisaurus (intercept) & 1.1285 & 0.1011 & 11.156 & $<0.0001$ \\
Total Crown Height & 0.0059 & 0.0035 & 1.714 & 0.0933 \\
(mm) & & & & \\
Undescribed & 0.3718 & 0.1148 & 3.237 & 0.0022 \\
Nundasuchus & 0.0995 & 0.1247 & 0.798 & 0.4290 \\
'Pallisteria' & -0.1249 & 0.2007 & -0.622 & 0.5369 \\
Parringtonia & 0.2490 & 0.1127 & 2.210 & 0.0321
\end{tabular}

1 


\section{Table 3(on next page)}

Pairwise comparisons of taxa used in the linear model.

A - summary table of Ismeans. B - summary table of pairwise comparisons. The undescribed pseudosuchian is readily differentiable from most taxa, with the exception of Parringtonia. Confidence intervals were generated using a 95\% confidence level. 
$1 \mathrm{~A}$

\begin{tabular}{llllll} 
Taxon & lsmeans & Standard Error & df & Lower CL & Upper CL \\
\hline Asilisaurus & 1.2354 & 0.1150 & 46 & 1.0039 & 1.4669 \\
Undescribed & 1.6071 & 0.0568 & 46 & 1.4929 & 1.7214 \\
Nundasuchus & 1.3348 & 0.0505 & 46 & 1.2332 & 1.4365 \\
'Pallisteria' & 1.1105 & 0.1225 & 46 & 0.8640 & 1.3570 \\
Parringtonia & 1.4844 & 0.0595 & 46 & 1.3645 & 1.6042
\end{tabular}

2

3 B

\begin{tabular}{llllll} 
Contrast & Estimate & SE & df & t ratio & p-value \\
\hline Asilisaurus - Undescribed & -0.3718 & 0.1148 & 46 & -3.237 & 0.0181 \\
Asilisaurus - Nundasuchus & -0.0995 & 0.1247 & 46 & -0.798 & 0.9299 \\
Asilisaurus - 'Pallisteria' & 0.1249 & 0.2007 & 46 & 0.622 & 0.9708 \\
Asilisaurus - Parringtonia & -0.2490 & 0.1127 & 46 & -2.210 & 0.1944 \\
Undescribed - Nundasuchus & 0.2723 & 0.0751 & 46 & 3.625 & 0.0062 \\
Undescribed - 'Pallisteria' & 0.4967 & 0.1571 & 46 & 3.162 & 0.0222 \\
Undescribed - Parringtonia & 0.1228 & 0.0677 & 46 & 1.813 & 0.3788 \\
Nundasuchus - 'Pallisteria' & 0.2244 & 0.1343 & 46 & 1.671 & 0.4614 \\
Nundasuchus - Parringtonia & -0.1495 & 0.0770 & 46 & -1.942 & 0.3107 \\
'Pallisteria' - Parringtonia & -0.3739 & 0.1631 & 46 & -2.292 & 0.1659
\end{tabular}

